\title{
Monitoring patient-ventilator interaction by an end-expiratory occlusion maneuver
}

\author{
Jose Dianti ${ }^{1,2}$, Michele Bertoni ${ }^{3}$ and Ewan C. Goligher ${ }^{1,2,4^{*}}$ (D)
}

(0) 2020 Springer-Verlag GmbH Germany, part of Springer Nature

\section{Patient-ventilator interaction during assisted mechanical ventilation}

Mechanical ventilation (in combination with sedation) can completely suppress patient respiratory drive and effort. While there are circumstances under which this may be desirable, maintaining spontaneous respiratory effort is generally preferred because it reduces atelectasis, improves oxygenation, reduces pulmonary vascular resistance, and may prevent disuse diaphragm atrophy [ 1 , 2]. Vigorous respiratory effort during assisted ventilation, however, can induce unintentional patient self-inflicted lung injury (P-SILI). Large respiratory efforts increase tidal volumes and elevate both global and regional lung stress, increasing the risk of volutrauma in the baby lung and exacerbating respiratory failure [3, 4]. Vigorous diaphragm contractions may also cause load-induced diaphragm injury [2]. Spontaneous breathing is, therefore, not a panacea, and its benefits and risks depend heavily on the magnitude of respiratory effort. Physiological principles and observational data suggest that a level of effort similar to that of resting quiet breathing is probably optimal [5].

Respiratory drive and effort also determine the risk of patient-ventilator asynchrony [6]. Asynchrony usually results either from low respiratory drive (ineffective efforts, reverse triggering), or from high respiratory drive and excessive effort (double triggering, flow starvation). Diagnosis and management of these asynchronies can be informed by an assessment of respiratory drive and effort.

*Correspondence: ewan.goligher@utoronto.ca

${ }^{1}$ Interdepartmental Division of Critical Care Medicine, University of Toronto, Toronto, Canada

Full author information is available at the end of the article
In sum, assessing and managing patient respiratory effort are central to optimizing patient-ventilator interaction and mitigating its potential adverse effects.

\section{The need for non-invasive techniques to monitor patient-ventilator interaction and respiratory effort}

Detecting adverse patient-ventilator interactions and excessive or insufficient respiratory effort is challenging. Respiratory rate is an unreliable indicator of respiratory effort as it is relatively unresponsive to changes in ventilatory loading and can be influenced by multiple factors [7]. Airway pressure and flow provide no direct information about inspiratory effort, though changes in effort can be suggested by changes in flow or pressure waveforms. Airway pressure is an unreliable marker to quantify global lung stress in the presence of respiratory effort, as it can underestimate the increased transpulmonary pressure generated by negative pleural pressure swings from the contraction of the inspiratory muscles [8]. Therefore, basic inspection of ventilator waveforms is not sensitive enough to rule out potentially injurious respiratory efforts [9].

Esophageal manometry can monitor patient-ventilator interaction by evaluating the presence and intensity of the respiratory effort based on the esophageal pressure swing $\left(\Delta \mathrm{P}_{\mathrm{es}}\right)$, estimating the pressure generated by the respiratory muscles $\left(\mathrm{P}_{\text {mus }}\right)$ [10]. However, as with other monitoring tools (i.e., diaphragm electrical activity), $\mathrm{P}_{\mathrm{es}}$ monitoring requires time, dedicated equipment, and some expertise to appropriately interpret the signals. Busy clinicians require simple, feasible, non-invasive techniques to evaluate patient-ventilator interaction and respiratory effort.

\section{勿




\section{Using a brief expiratory occlusion maneuver to detect adverse patient-ventilator interactions}

When an end-expiratory airway occlusion is applied at random for the duration of a single inspiratory effort (or up to $5 \mathrm{~s}$ ), spontaneous respiratory effort by the patient during the occlusion will generate a negative pressure deflection in the airway pressure that 'unmasks' the respiratory muscle effort (Fig. 1a). The magnitude of the negative pressure deflection during the occlusion (Pocc) is correlated with $\mathrm{P}_{\text {mus }}$ during mechanically assisted breaths, because a single end-expiratory occlusion applied intermittently at random for a single breath does not alter the magnitude of diaphragm activation [11].

Pocc can be used to estimate both $P_{\text {mus }}$ and the dynamic transpulmonary driving pressure $\left(\Delta \mathrm{P}_{\mathrm{L}, \text { dyn }}\right)$, a measure of the dynamic mechanical stress applied to the lung during inspiration. $\mathrm{P}_{\text {mus }}$ and $\Delta \mathrm{P}_{\mathrm{es}}$ can be estimated from Pocc by validated correction factors that adjust for chest wall elastance and the difference in chest wall kinematics between occluded and non-occluded conditions (Fig. 1a). $\Delta \mathrm{P}_{\mathrm{L}, \text { dyn }}$ can then be estimated by subtracting the estimated $\Delta \mathrm{P}_{\mathrm{es}}$ from the positive airway pressure swing during assisted breaths (Fig. 1a). Of note, $\Delta \mathrm{P}_{\mathrm{L} \text {,dyn }}$ may be a better reflection of peak regional lung stress than quasistatic transpulmonary driving pressure [12]. Although optimal values for these parameters have not been established, estimated $\mathrm{P}_{\text {mus }}>15 \mathrm{~cm} \mathrm{H}_{2} \mathrm{O}$ and estimated $\Delta \mathrm{P}_{\mathrm{L} \text {,dyn }}>20 \mathrm{~cm} \mathrm{H} \mathrm{H}_{2} \mathrm{O}$ indicate that respiratory effort and dynamic lung stress, respectively, are likely excessive [11].

Using this simple method, clinicians can detect (a) excessive respiratory effort from the estimated value for $\mathrm{P}_{\text {mus }}$ (b) absent respiratory effort during apnea (no pressure deflection during the $5 \mathrm{~s}$ occlusion), and (c) excessive lung stress during spontaneous breathing from the estimated value for $\Delta \mathrm{P}_{\mathrm{L} \text {,dyn. }}$. Thus, the key parameters reflecting potential risk of diaphragm and lung injury can be readily and reliably detected by measuring Pocc. The maneuver can also be used to monitor patients receiving neuromuscular blockade to confirm the absence of respiratory effort; if there is no negative deflection in airway pressure during a $5 \mathrm{~s}$ occlusion (i.e., $\mathrm{Pocc}=0 \mathrm{~cm}$ $\mathrm{H}_{2} \mathrm{O}$ ), adequate paralysis has likely been achieved. The sensitivity of this approach has not yet been directly compared against other commonly used methods to assess the adequacy of neuromuscular blockade (i.e., peripheral nerve stimulation).

Finally, an expiratory occlusion can differentiate various dyssynchronies. For example, the expiratory occlusion may unmask ineffective triggering if the patient's intrinsic respiratory rate is much higher during the occlusion than is apparent during the assisted breaths. When double cycling is observed, an end-expiratory occlusion will reveal whether this results from excessive and prolonged inspiratory effort or from reverse triggering (in which case the patient will generally be apneic during the pause) (Fig. 1b). If the ventilator appears to be triggered by the patient, but there are no respiratory efforts during the occlusion, then autotriggering is likely (Figure E1, Online Supplement).

\section{Limitations}

This method has limitations. First, although Pocc can be used to accurately detect excess $\mathrm{P}_{\text {mus }}$ and $\Delta \mathrm{P}_{\mathrm{L} \text {,dyn }}$, the estimated values of these parameters are imprecise and cannot replace direct measurement if precision is required. Second, the absence of respiratory effort during the occlusion does not rule out the presence of respiratory effort from reverse triggering (Fig. 1b). Finally, dynamic hyperinflation and intrinsic PEEP might lead to underestimation of the effort, particularly if intrinsic PEEP has not equilibrated against the occluded airway.

\section{Conclusion}

An expiratory occlusion maneuver is a simple, feasible, and non-invasive method of evaluating patient-ventilator interaction. The maneuver can detect absent or excessive respiratory effort or excessive dynamic lung stress and can be used to differentiate various forms of patient-ventilator dyssynchrony. This maneuver may provide a basic monitoring approach for lung and diaphragm-protective ventilation ('safe spontaneous breathing') to be tested in future clinical trials. 
A

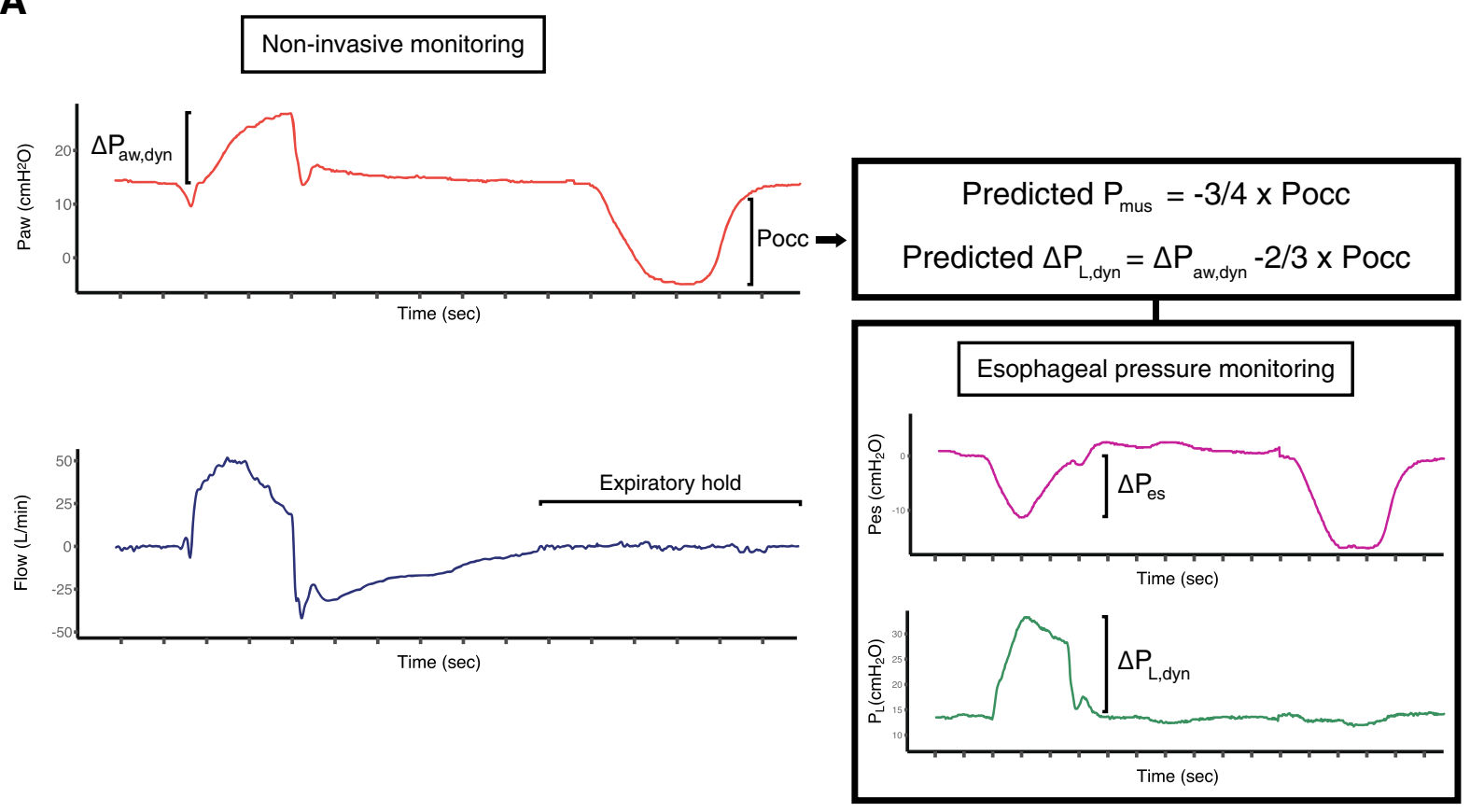

B

Reverse triggering

Double triggering
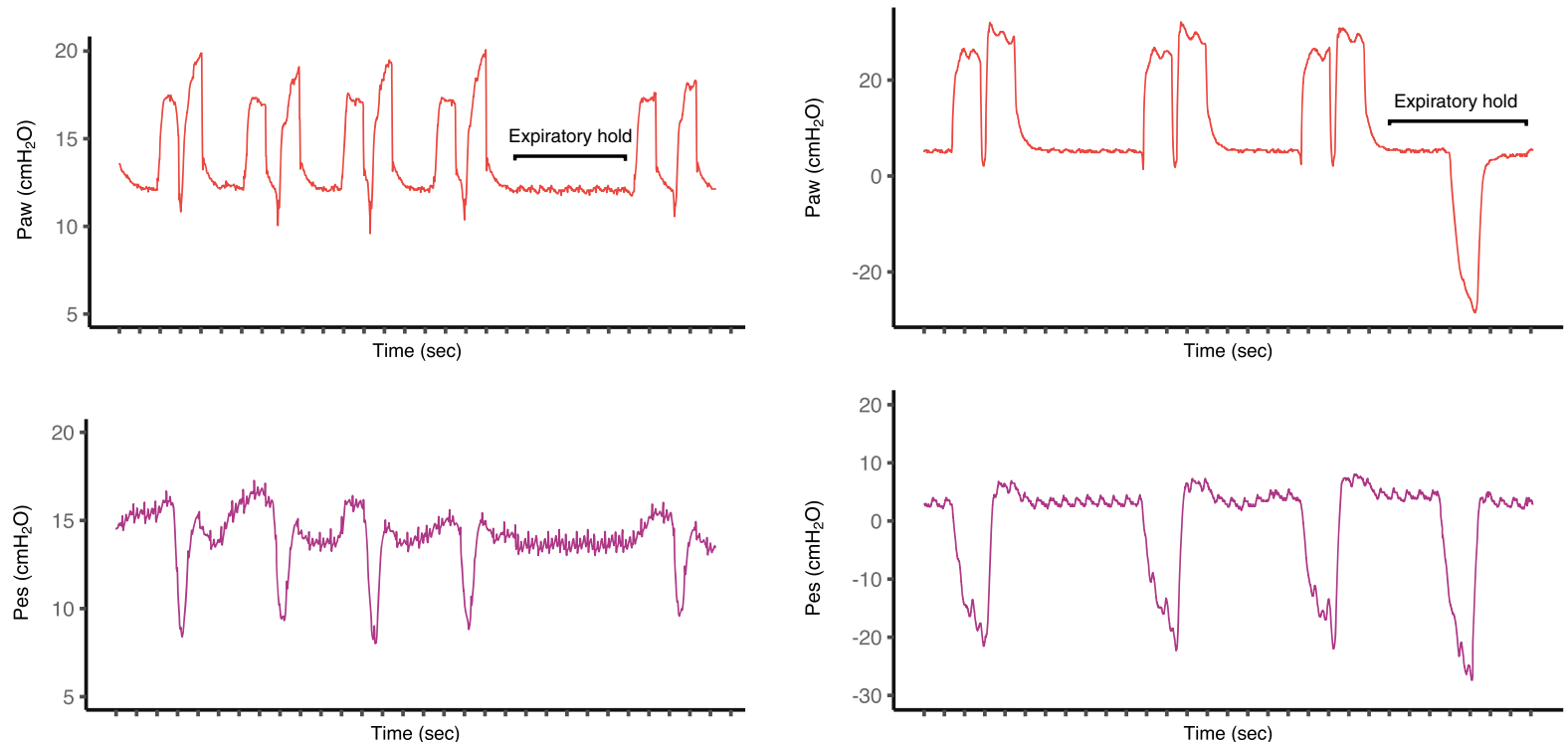

Fig. 1 Representative tracings showing a) the airway occlusion maneuver in a spontaneously breathing patient at rest, and b) two patients with double triggering; one resulting from reverse triggering and the other resulting from a dissociation between neural and mechanical inspiratory time. Airway pressure $\left(P_{a w}\right)$, flow, esophageal pressure $\left(P_{e s}\right)$, and transpulmonary pressure $\left(P_{L}\right)$ were recorded during the expiratory occlusion maneuver. $P_{\text {occ }}$ represents the inspiratory swing in airway pressure against an occluded airway. $\Delta P_{\text {es }}$ represents the dynamic esophageal pressure inspiratory swing. The dynamic transpulmonary driving pressure $\left(\Delta \mathrm{P}_{\mathrm{L}, \mathrm{dyn}}\right)$ represents the dynamic mechanical stress applied to the lung during inspiration. By applying previously validated correction factors, clinicians can use $P_{\text {occ }}$ to estimate respiratory muscle effort $\left(P_{\text {mus }}\right)$ and $\Delta P_{L, d y n}$. In panel $\mathbf{b}$, during the expiratory hold, there is no respiratory effort from the patient with reverse triggering, signifying that the double triggering is occurring in the absence of spontaneous respiratory drive. Conversely, an inspiratory effort can be seen during the hold in the other patients' tracing 


\section{Electronic supplementary material}

The online version of this article (https://doi.org/10.1007/s00134-020-06167-3) contains supplementary material, which is available to authorized users.

\section{Author details}

1 Interdepartmental Division of Critical Care Medicine, University of Toronto, Toronto, Canada. ${ }^{2}$ Department of Medicine, Division of Respirology, University Health Network, Toronto, Canada. ${ }^{3}$ Department of Anesthesia, Critical Care and Emergency, Spedali Civili University Hospital, Brescia, Italy. ${ }^{4}$ Toronto General Hospital Research Institute, 585 University Ave., 11-PMB Room 192, Toronto, ON M5G 2N2, Canada.

\section{Acknowledgements}

The authors would like to thank Dr. Benjamin Coiffard for his help collecting the tracings.

\section{Funding}

Dr. Goligher is supported by an Early Career Investigator Award from the Canadian Institutes of Health Research.

\section{Compliance with ethical standards}

\section{Conflicts of interest}

On behalf of all the authors, the corresponding author states that there is no conflict of interests.

\section{Publisher's Note}

Springer Nature remains neutral with regard to jurisdictional claims in published maps and institutional affiliations.

Received: 13 April 2020 Accepted: 24 June 2020

Published online: 4 July 2020

\section{References}

1. de Abreu MG, Güldner A, Pelosi P (2012) Spontaneous breathing activity in acute lung injury and acute respiratory distress syndrome. Curr Opin Anaesthesiol 25:148-155. https://doi.org/10.1097/aco.0b013e3283504bd e
2. Goligher EC, Brochard LJ, Reid WD et al (2018) Diaphragmatic myotrauma: a mediator of prolonged ventilation and poor patient outcomes in acute respiratory failure. Lancet Respir Med 7:90-98. https://doi.org/10.1016/ s2213-2600(18)30366-7

3. Yoshida T, Roldan R, Beraldo MA et al (2016) Spontaneous effort during mechanical ventilation. Crit Care Med 44:e678-e688. https://doi. org/10.1097/ccm.00000000

4. Tonelli R, Fantini R, Tabbì L et al (2020) Inspiratory effort assessment by esophageal manometry early predicts noninvasive ventilation outcome in de novo respiratory failure: a pilot study. Am J Resp Crit Care. https:// doi.org/10.1164/rccm.201912-2512oc

5. de Vries H, Jonkman A, Shi Z-H et al (2018) Assessing breathing effort in mechanical ventilation: physiology and clinical implications. Ann Transl Med 6:387-387. https://doi.org/10.21037/19953

6. Chanques G, Kress JP, Pohlman A et al (2013) Impact of ventilator adjustment and sedation-analgesia practices on severe asynchrony in patients ventilated in assist-control mode. Crit Care Med 41:2177-2187. https:// doi.org/10.1097/ccm.0b013e31828c2d7a

7. Brochard L, Telias I (2018) Bedside detection of overassistance during pressure support ventilation. Crit Care Med 46:488-490. https://doi. org/10.1097/ccm.0000000000002913

8. Bellani G, Pesenti A (2014) Assessing effort and work of breathing. Curr Opin Crit Care 20:352-358. https://doi.org/10.1097/mcc.0000000000 000089

9. Georgopoulos D, Prinianakis G, Kondili E (2006) Bedside waveforms interpretation as a tool to identify patient-ventilator asynchronies. Intens Care Med 32:34-47. https://doi.org/10.1007/s00134-005-2828-5

10. Yoshida T, Brochard L (2018) Esophageal pressure monitoring. Curr Opin Crit Care 24:216-222. https://doi.org/10.1097/mcc.0000000000000494

11. Bertoni M, Telias I, Urner M et al (2019) A novel non-invasive method to detect excessively high respiratory effort and dynamic transpulmonary driving pressure during mechanical ventilation. Crit Care 23:346. https:// doi.org/10.1186/s13054-019-2617-0

12. Yoshida T, Amato MBP, Kavanagh BP (2018) Understanding spontaneous vs. ventilator breaths: impact and monitoring. Intens Care Med 44(12):2235-2238. https://doi.org/10.1007/s00134-018-5145-5 